招待講演ＪIPE-32-1

\title{
パワエレ技術最前線と 今後の進むべき方向
}

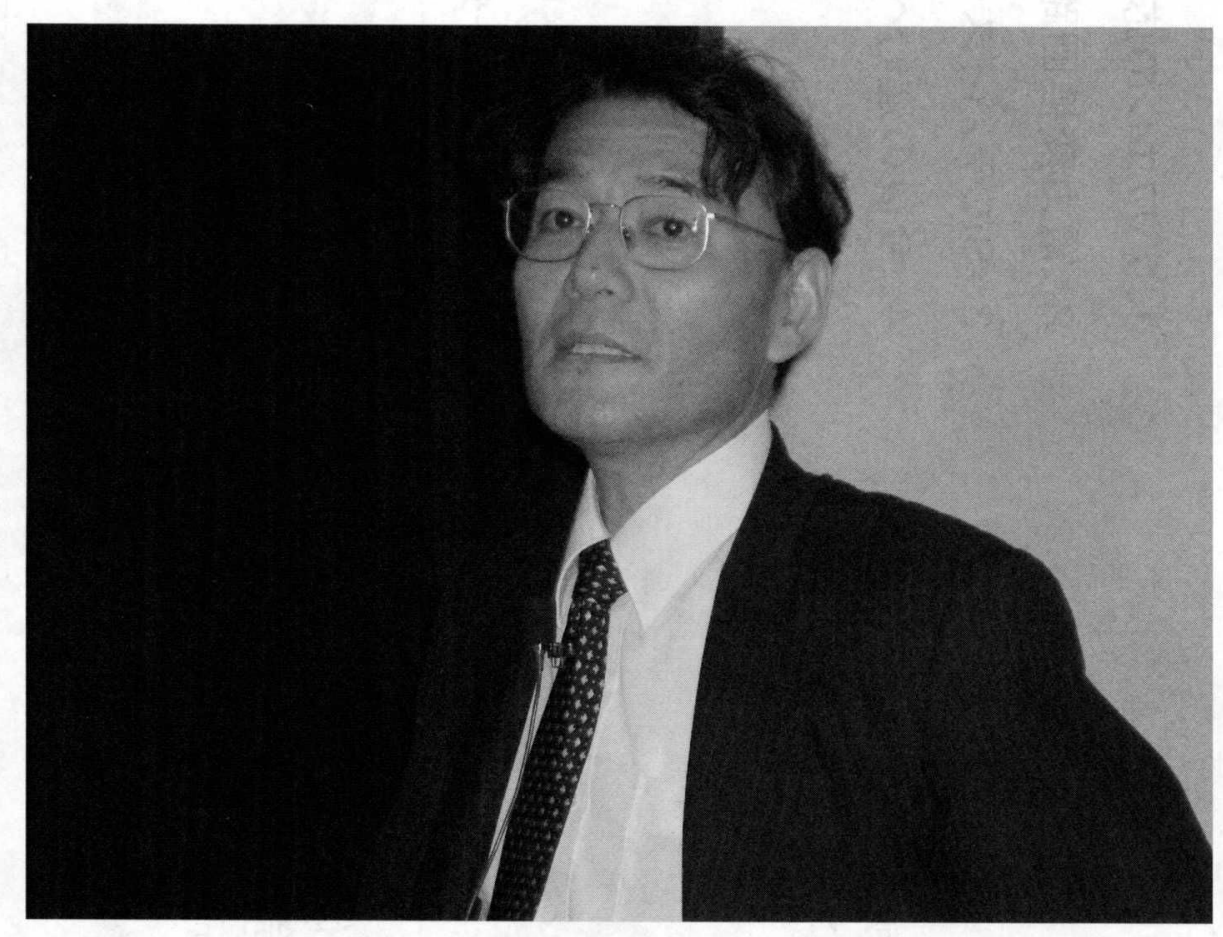

\section{三菱電機株式会社 小山 正人}




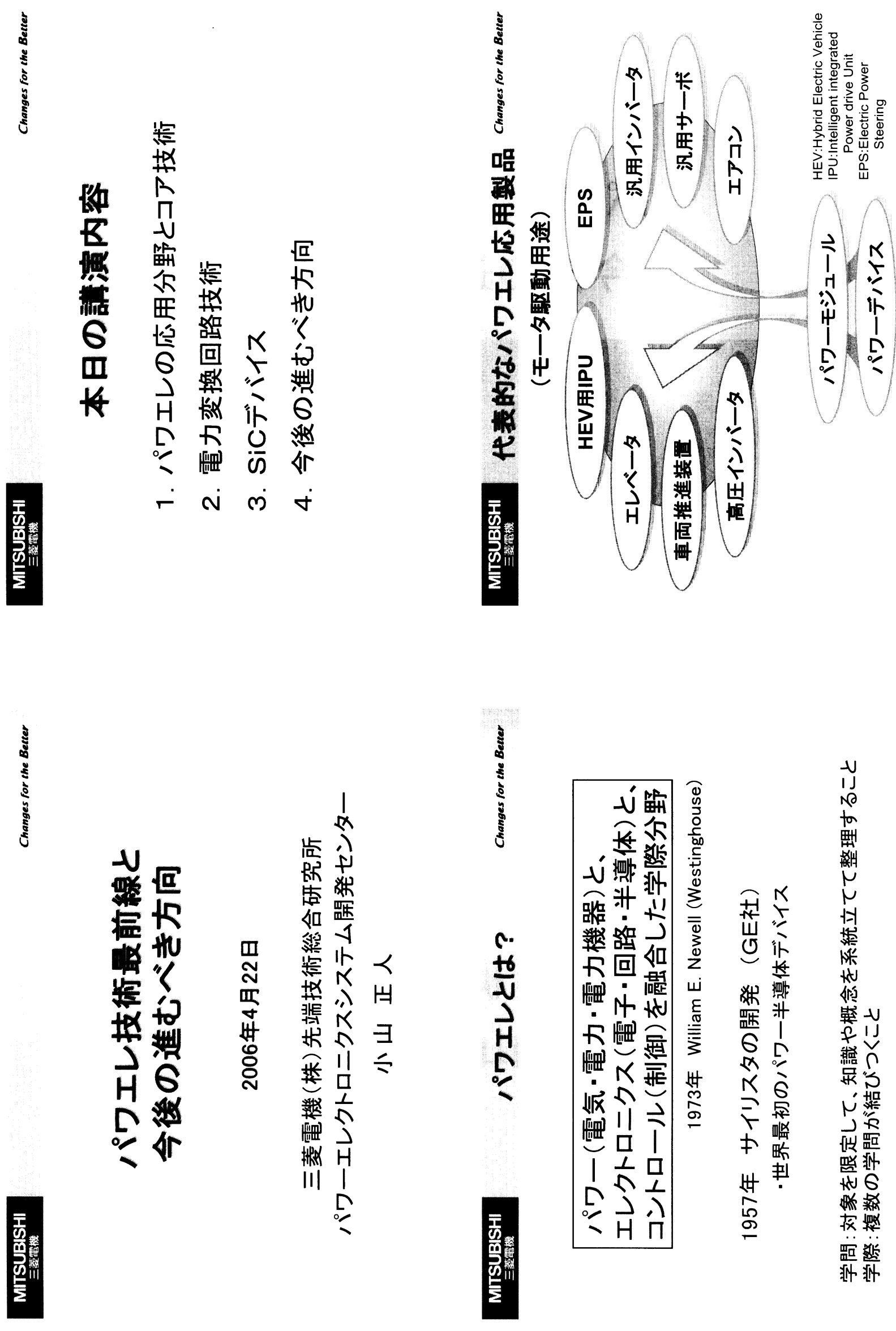



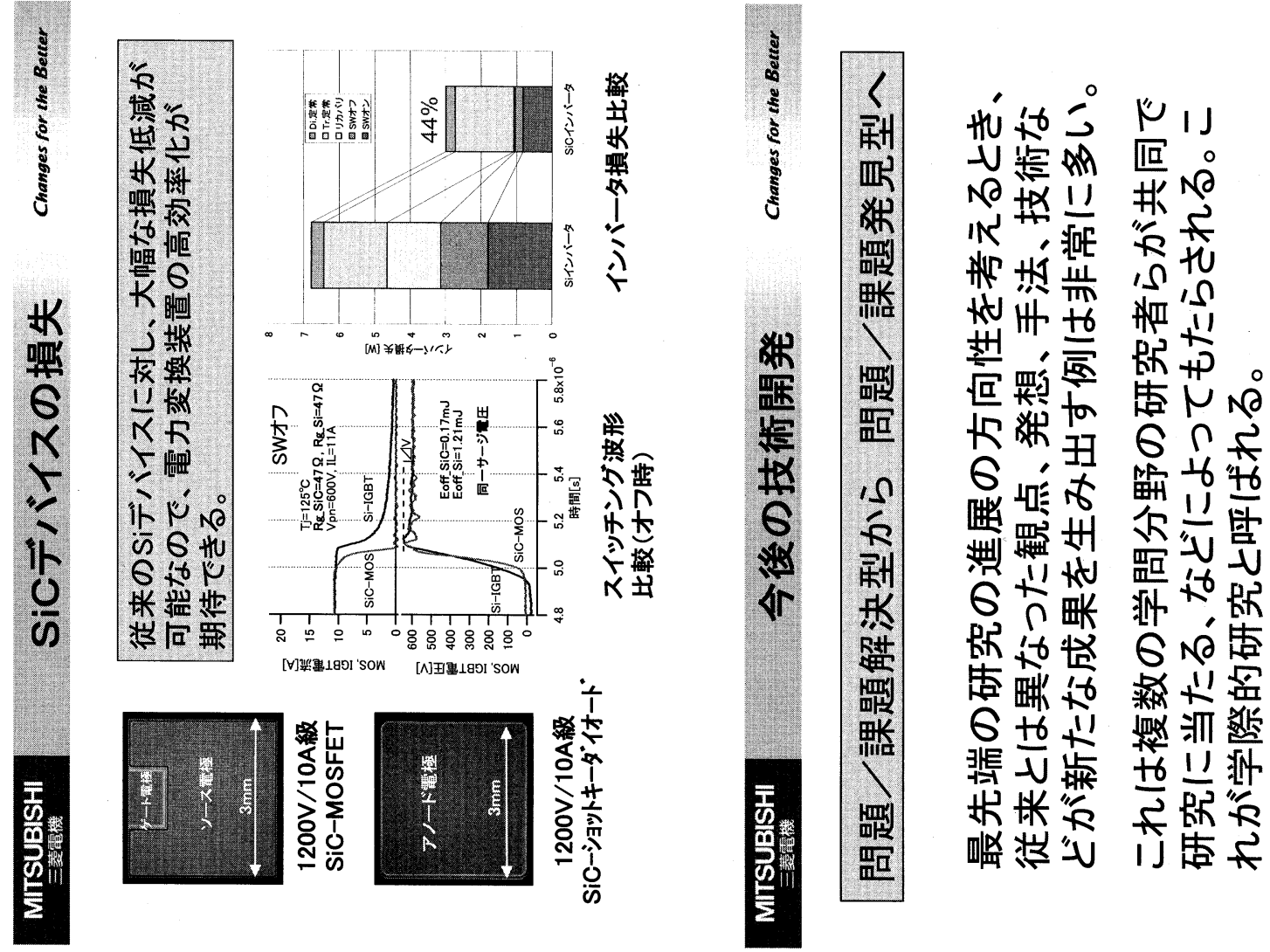

אֶ.
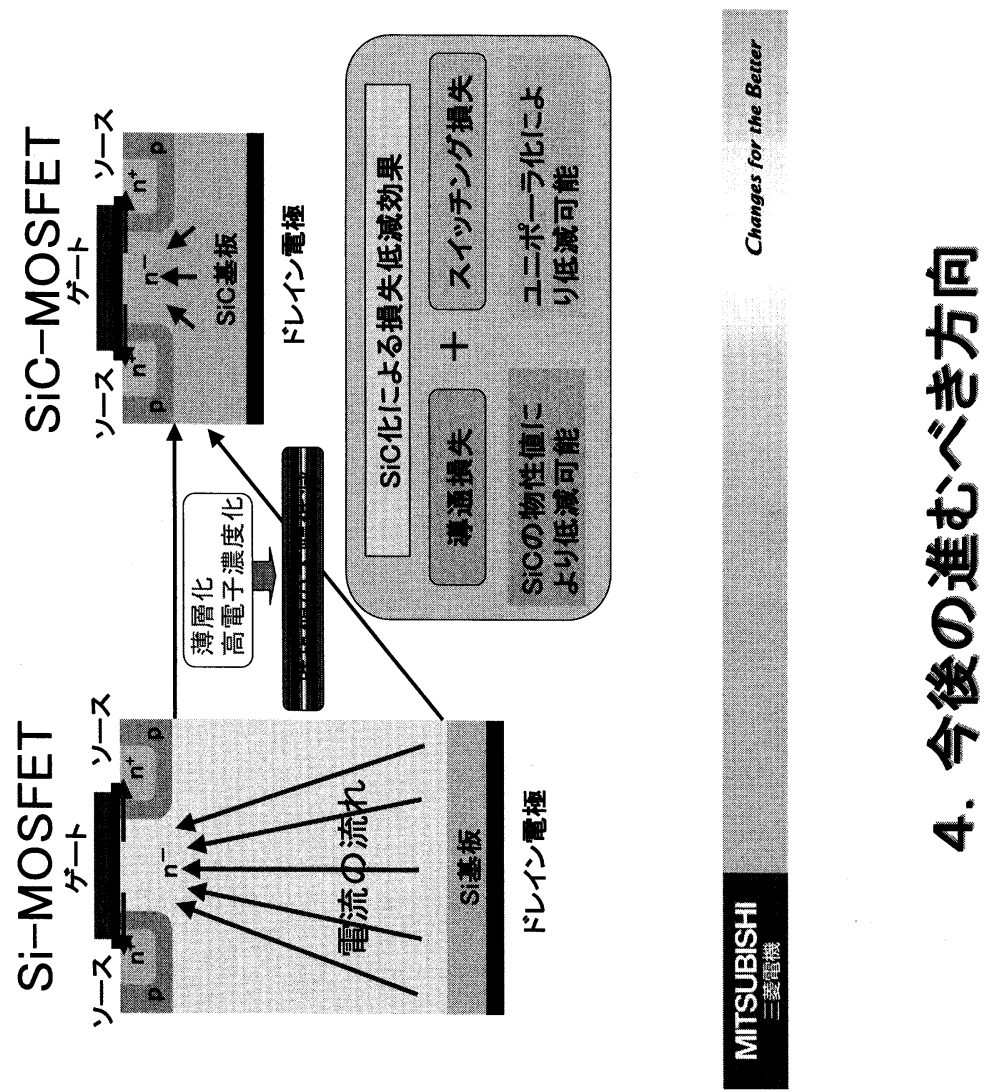

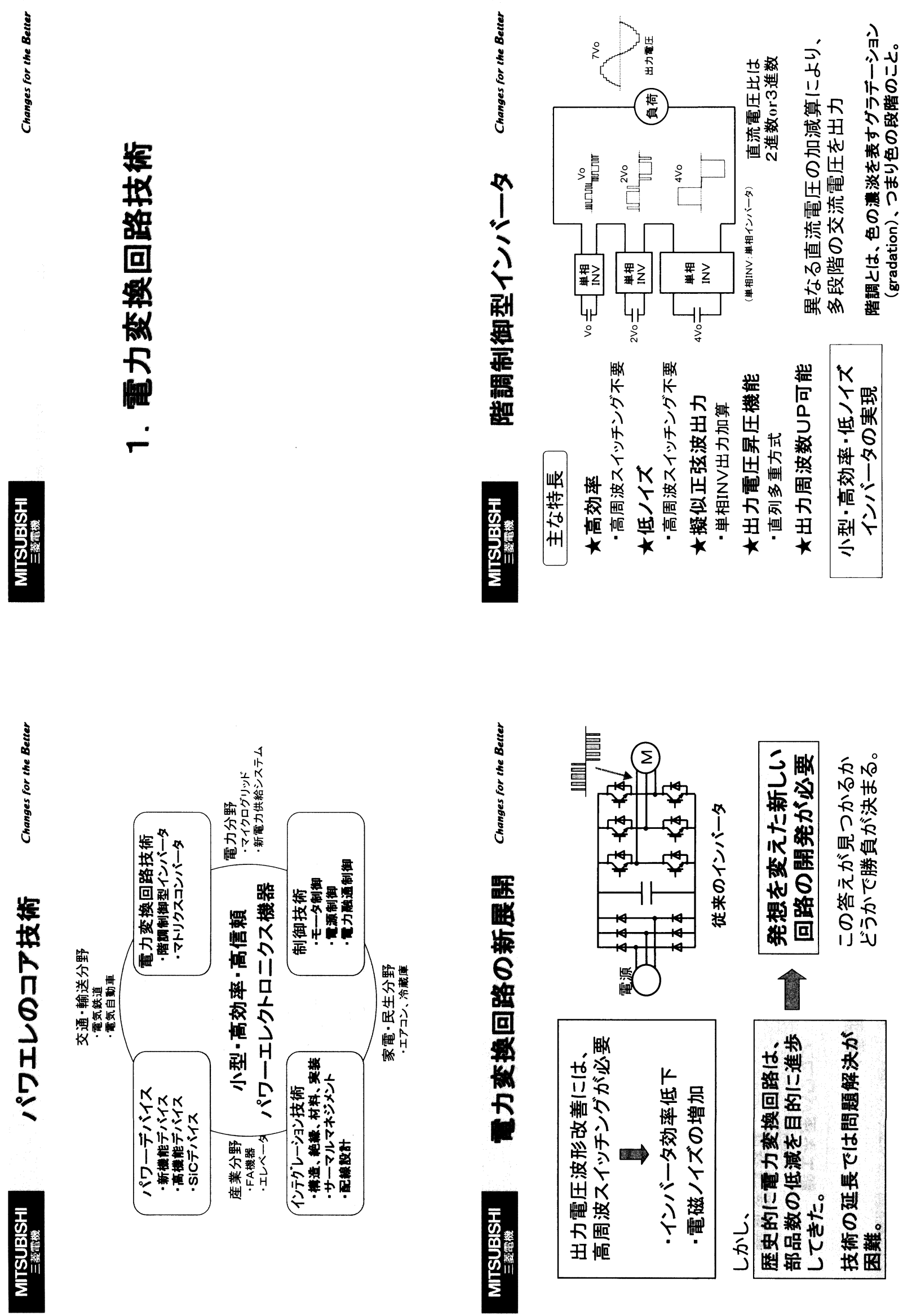

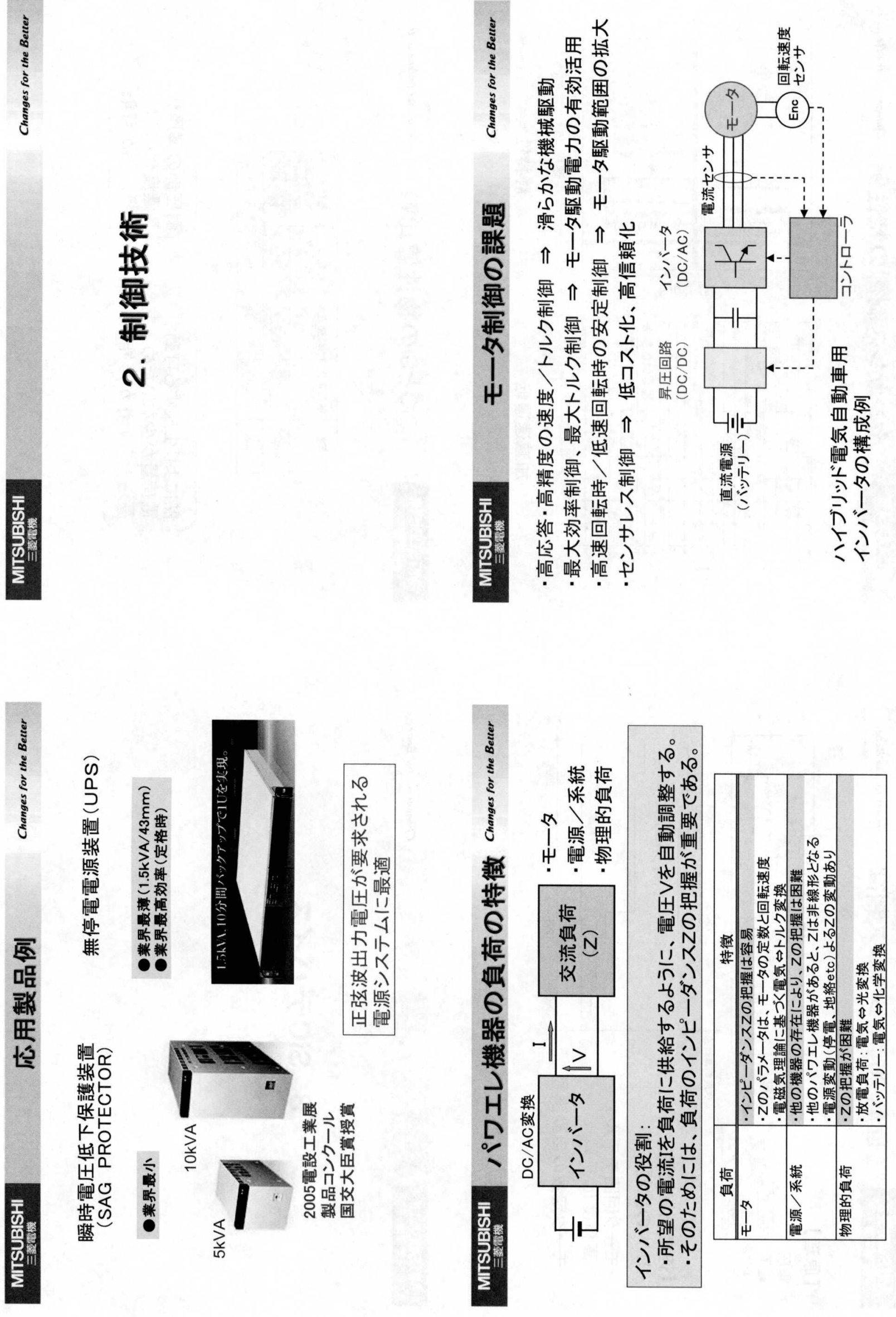

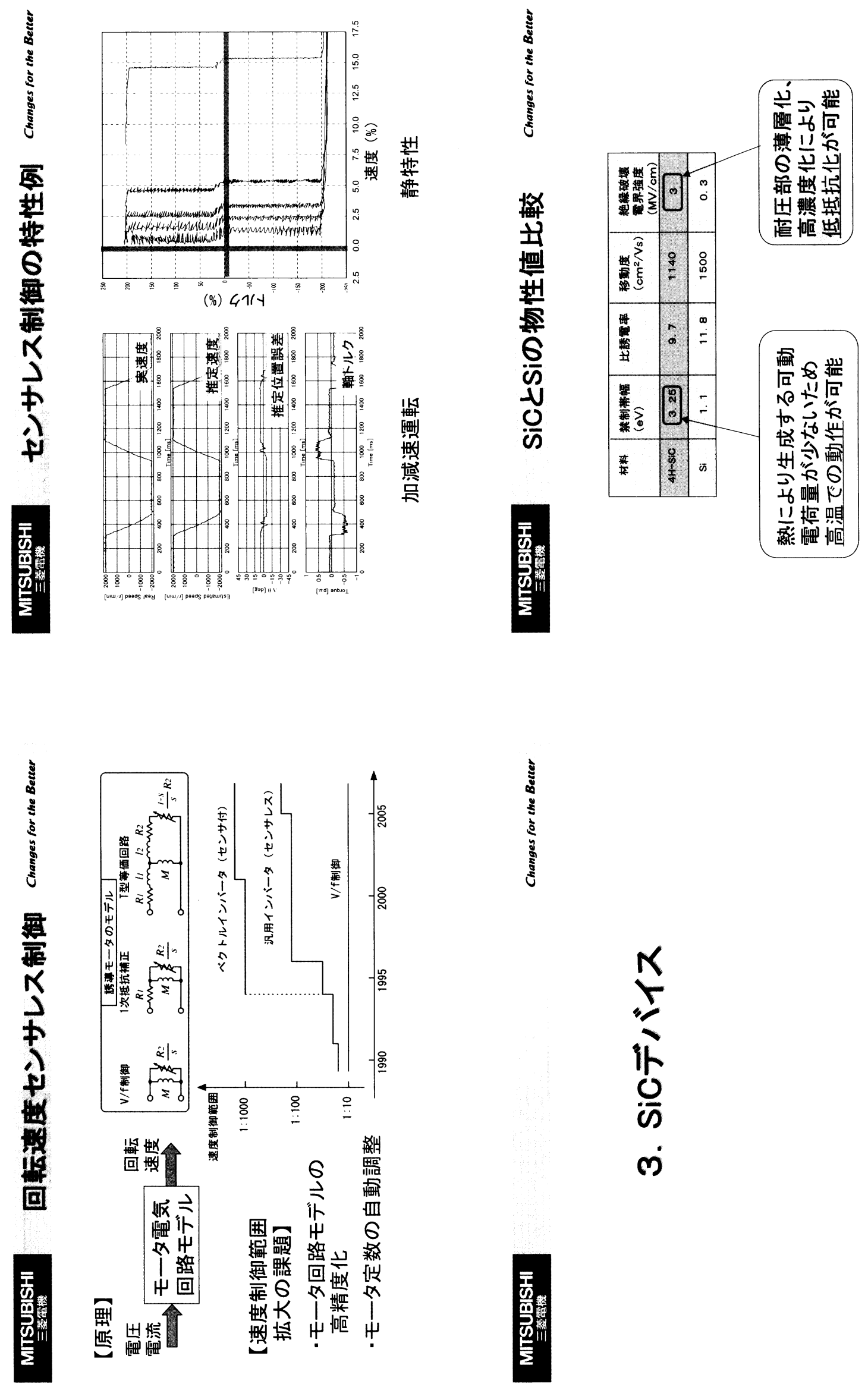

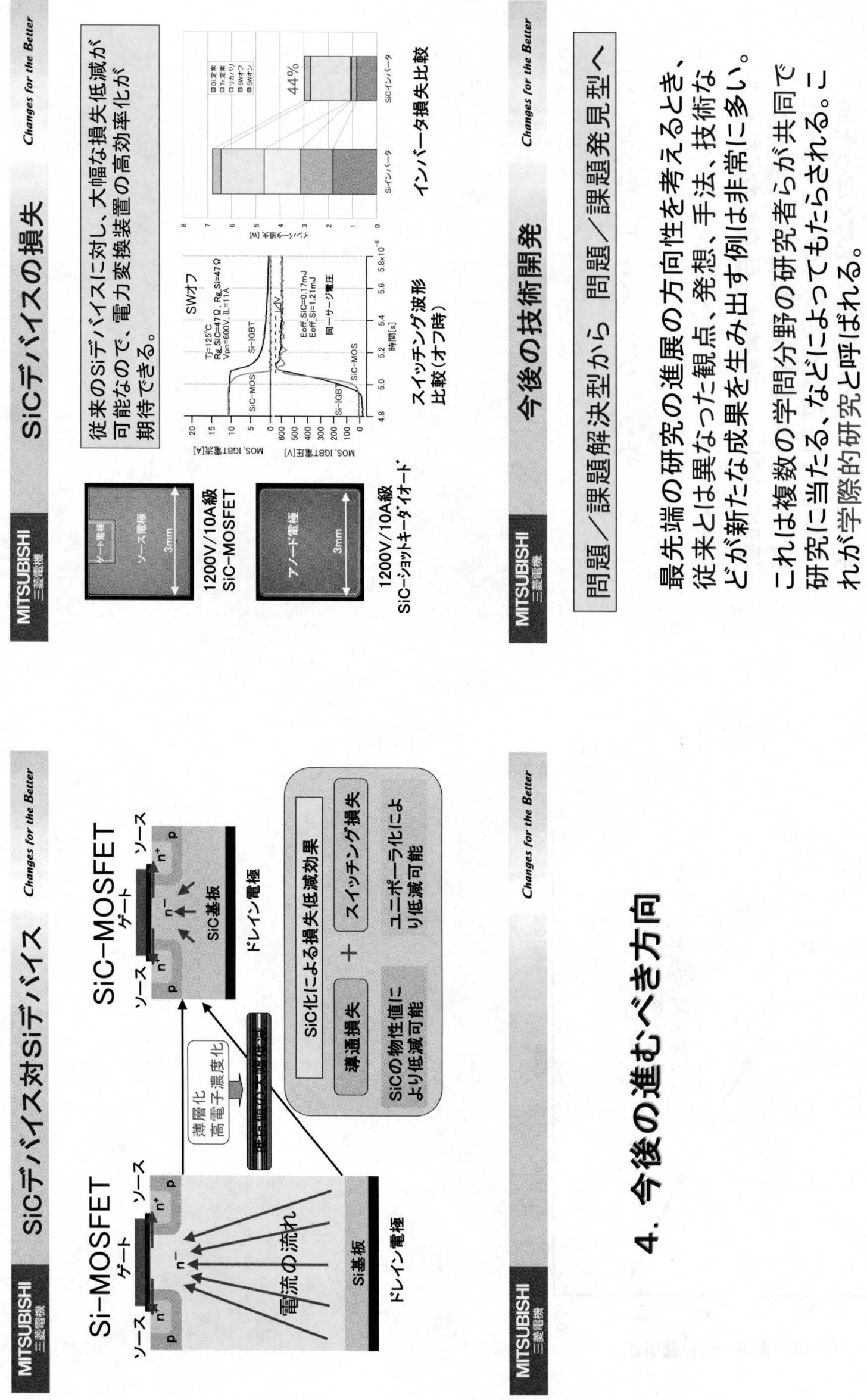


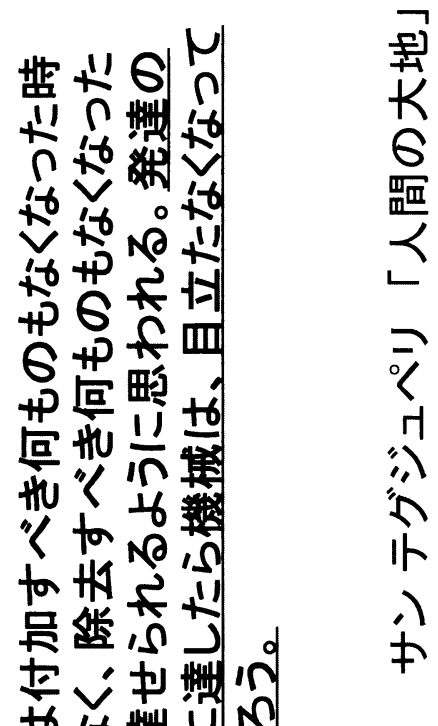

蛋

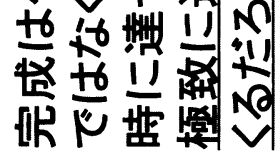

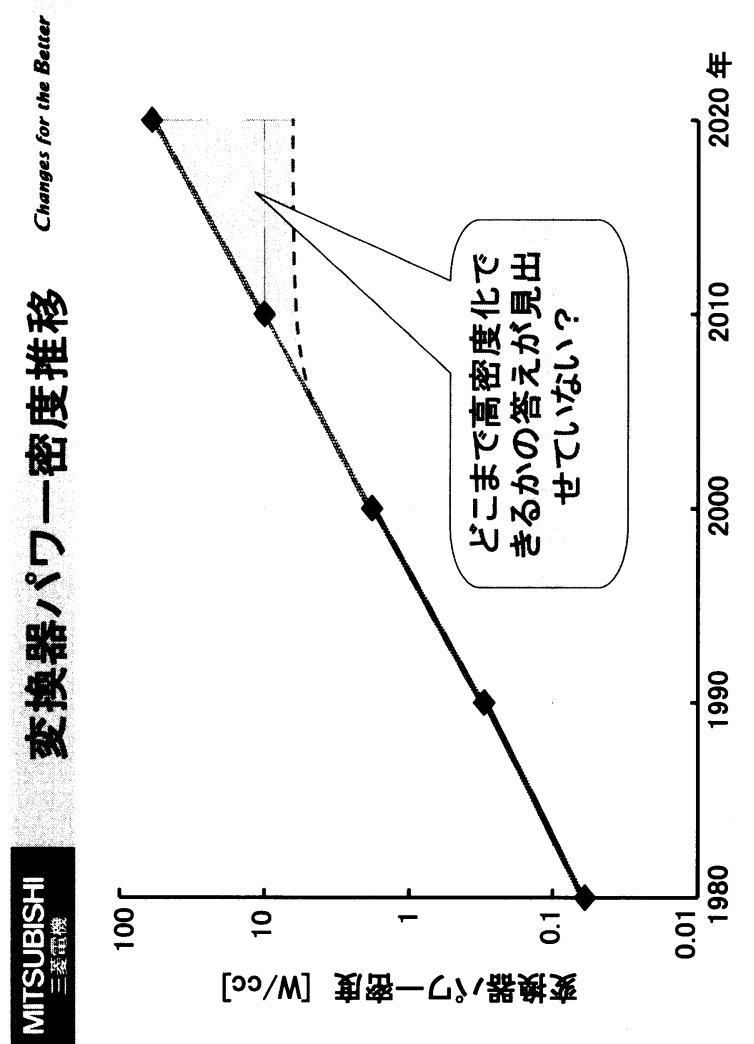

